European Association for the Development of Renewable Energies, Environment and Power Quality
International Conference on Renewable Energies and Power Quality (ICREPQ’09)

Valencia (Spain), 15th to 17th April, 2009

\title{
The Impact of Transportation Costs on the Profitability of Heat and Power Generation with Wood Products
}

\author{
J. Parrilla ${ }^{1}$ and W. Fichtner ${ }^{2}$ \\ ${ }^{1}$ Chair of Energy Economics \\ Brandenburg Technical University of Cottbus \\ Walther-Pauer-Str. 5, LG 3 \\ D-03046 Cottbus (Germany) \\ Phone: +49 17696030585, e-mail: javier.parrillamartinez@tu-cottbus.de \\ ${ }^{2}$ Chair of Energy Economics \\ Institute for Industrial Production \\ Universität Karlsruhe (TH) \\ Hertzstr. 16 \\ D-76187 Karlsruhe (Germany) \\ Phone: +49 721608 4460, Fax: + 49721 758909, e-mail: wolf.fichtner@wiwi.uni-karlsruhe.de
}

\begin{abstract}
International markets for wood biomass are currently emerging. Due to the corresponding environmental benefits, the domestic wood combustibles are an important energy resource, although certain measures must be taken to make the supply chain more cost-effective and efficient.

One of the major contributors to the costs of wood products is transportation, which is determined by the geographical location of forests and energy crops. Within this paper techno-economic parameters of all substantial process steps along the biomass value chain are estimated. The potential for logs and chips, which includes justifiable transportation distances for these kinds of biomass, will be analyzed. To reach these objectives a simulation model has been developed. The results may be used for socioeconomical resource allocation and planning of future energy plants.
\end{abstract}

\section{Key words}

Chips, HPS (heat and power station), logistic chain, logs, transportation costs.

\section{Introduction}

The production of heat and electricity is nowadays influenced by the effect of climate change through the exhaust gases derived from the combustion of fossil fuels. The use of wood as raw material from tree plantations, natural woods and agricultural and industrial wastes represents a solution to diminish the $\mathrm{CO}_{2}$ concentration and thereby reduce the Greenhouse effect. The construction of Bio Heat and Power Stations (HPS) to be fueled with biomass in form of wood-based products like chips or logs constitutes an interesting step to both producing clean energy and promoting the agricultural and wooded areas.

However biomass transport from fields to HPSs contributes significantly to the production costs due to the low energy density of wood as well as its large volume. These both parameters make biomass use an excessively costly energy activity especially with regard to the most cost-sensitive step of the biomass value chain: transportation [1]. In order to minimize these costs and make wood products economically competitive regarding fossil fuels a complete logistic analysis from an economic point of view has been accomplished.

\section{Objectives}

The wood products analyzed in this work are chips and logs considered apart from pellets or briquettes resulting from a densification process. The production costs of this second group of wood products are higher although their energy per mass unit is also higher. Due to this reason the subject of this study was only focused on the two firstly abovementioned biomass fuels, which are comparable regarding their final applicability for energy generation on an industrial scale and regarding relatively short transportation distances. For both fuels the corresponding biomass value chains have to be scrutinized by economically analyzing each of the steps happening from felling the trees up to their conversion into energy.

Economic and technical data for each element belonging to the biomass value chain have been collected so that the 
profitability of the energy generation process in direct competition with that of oil-derived fuels can be assessed for the biomass obtained in areas situated around the HPS. These data are especially related to transportation but they likewise involve the parameters concerning all the value chain for the logistic chains of logs and chipped branches.

Another decisive aim accomplished in the course of this investigation consisted in establishing a model based on a region centered around the HPS, thereby determining the area comprising those forests and cultivation fields which are at such a distance that biomass transportation can be considered as economically competitive. Within a given district and for its corresponding biomass resources a spatial allocation of the productive areas should be realized by identifying a cluster of energy producers along with their corresponding catchment area where biomass appears to be competitive with fossil fuel-based energy generation.

In order to elaborate all the collected data a simulation tool has been implemented thereby modeling the economic reality involved in the process of heat and power generation from biomass resources.

\section{Subject of the study: the wood raw material}

The forests and some cultivation lands like those of fruit trees and other wood crops represent a significant resource of wood biomass in many areas predominantly located in temperate and tropical regions of the world. The energy use of these biomass stocks could worldwide signify a relevant contribution to the reduction of Greenhouse gases and the diversification of any national energy mix.

Wood logs and wood branches are the most extended and important biomass source derived from forest areas. Other possible options would include the short rotation plantation and the rests of agricultural and industrial activities, thereby completing the whole bio-energy range for provision of wood to the respective logistic chains. Short rotation plantations constitute a very promising alternative although its still high production costs induced by the cost intensive cultivation processes continue to limit its consumption for power and heat generation. Therefore the wood fraction derived from forest areas and woods as well as the wood agricultural wastes will solely be considered for the purposes of the present study.

\section{Framework conditions for the study}

\section{A. Means of transport}

The wood required for the generation of power and heat usually occurs in natural forests as well as agricultural areas quite often showing some difficulties for access with most of the conventional motor vehicles. Other alternatives for transportation of wood like railway or ship have not been allowed for in this work because these means of transport either are used for covering long distances or require as in the case of ship transportation adequate and long enough waterways. This is not the assumption in this case and therefore only trucks with a volumetric carrying capacity of around $36 \mathrm{~m}^{3}$ were taken into account in the different logistic chains submitted to analysis [2]. Reference [3] also refers to bigger carrying capacities for transportation of solid biomass (logs, chips and bundles), ranging from $60 \mathrm{~m}^{3}$ to $93 \mathrm{~m}^{3}$. Nevertheless these capacities are exclusively oriented to cover long distances without having to access woodlands and cultivated areas.

Table I gathers all the necessary techno-economic data related to the kind of truck chosen for the transportation of wood. This information was taken from sources [2], [3] and [4].

Table I. - Techno-economic Data of the Means of Transport (Truck)

\begin{tabular}{lcc}
\hline \multicolumn{1}{c}{ Technical Data } & Units & \\
\hline Speed & $\mathrm{km} / \mathrm{h}$ & 50 \\
Carrying capacity & $\mathrm{m}^{3}$ & 36 \\
Fuel consumption & $1 / \mathrm{km}$ & 0.6 \\
\multicolumn{1}{c}{ Economic Data } & $\mathrm{Units}$ & \\
& & \\
\hline Salary of driver & $€ / \mathrm{h}$ & 20 \\
Truck costs & $€ / \mathrm{h}$ & 46 \\
Diesel price & $€ / 1$ & 1.10 \\
\hline \hline
\end{tabular}

\section{B. Specific framework for energy generation}

For the carrying out of the economic analysis of each of the biomass value chains studied in this paper an identification of a real region was required in order to be able to determine a true scenario through which the analytic process operated by the simulation tool can be adjusted to reality and thus become realistic enough.

Germany as a country was chosen for this purpose on account of its advanced legislation in the sector of renewable energies and more concretely on the subsidies granted for the power generation from biomass resources. The German Act for Renewable Energies (EEG) came first into force on April $1^{\text {st }}, 2000$. Thereafter several amendments (2004 and 2009) have been passed until nowadays introducing some modifications respecting the remuneration obtained through processes of power generation involving biomass resources. In this regard the revision of the year 2004 [5] was taken as valid reference for the economic analysis realized in this study once the overall economic data were also collected from works published around that year. This last fact would justify the coherence and reliability of this work without the necessity of updating costs and prices to their real value in 2008 or 2009. With regard to the real figures contributed by this act the most important parameters to be allowed for are the following: $8.9 €$ cent/ $\mathrm{kWh}_{\mathrm{el}}$ for those HPS with electric capacity up to $5 \mathrm{MW}$ and $8.4 €$ cent/ $/ \mathrm{WWh}_{\mathrm{el}}$ for facilities with 
an electric capacity larger than $5 \mathrm{MW}$. The heat stations receive no subsidies [5].

On the other hand each energy market has particular reference costs for the production of power and heat generated with fossil fuels. These costs are required for referring the production costs of the energy obtained from biomass to those generated with fossil fuels with the aim of evaluating the potential and profitability of wood as energy resource. For the present economic analysis the production costs of heat generation in Germany were set at 3.5 $€$ cent $/ \mathrm{kWh}$ (the value have been assumed as valid for the period of time concerned in the investigation).

\section{Technical conditions for wood}

There are two natural ways for occurring of wood products when collected from forests and agricultural areas (wood crops): the $\log$ and the branch. The former comes up as simple trunks put into a pile either on the truck trailer or in certain boxes being loaded on the trailer. The latter follows a process of chipping -according to the feasible processings analyzed in this work, where bundling was excluded - in order to reduce its volume and to consequently increase its energy density. This chipped bulk material is then easily treated and transported by means of pouring into containers.

For the current study four different wood types (spruce, pine, beech and oak) were taken into account for determining the average value for some of the involved physical properties as the density and the heating value both referred to the corresponding water content [6]-[7]. Table II shows the different properties for both chips and logs.

Table II. - Properties of Wood Products

\begin{tabular}{lccc}
\hline \hline & Units & Logs & Chips \\
\hline Density & $\mathrm{kg} / \mathrm{m}^{3}$ & 408.27 & 234.5 \\
Heating value & $\mathrm{kWh} / \mathrm{kg}$ & 4.025 & 4.025 \\
Water content & $\%$ & 18 & 18 \\
\hline \hline
\end{tabular}

Furthermore [7] gives these properties for wood regarding two different water contents: $50 \%$ and $18 \%$. This magnitude reveals the quantity of water contained in the wood and is desired to be as low as possible in order to facilitate the subsequent combustion process. Recently harvested wood usually has a water content of $50 \%$ what turns out to be extremely high for being used as biomass resource for energy generation purposes. Hence a necessary drying process already has to be carried out just after felling or thinning of trees by leaving the wood on the surfaces of fields and forests for periods of several months. During this process, water contents not lower than $20 \%$ are reached before wood is transported and then stored at the storage/conversion sites, where water content rates of around $18 \%$ are to be measured either by a further drying

process using the heat produced by the HPS or by simply sheltering the wood material from weather conditions.

\section{Technologies for firing wood biomass}

\section{A. Boiler}

Special boilers fired with wood biomass or more concretely with wood chips present a large power range. For this study a $5,000 \mathrm{~kW}_{\text {th }}$ boiler was considered as a representative heating unit used for industrial objectives. Reference [8] provides the main technical characteristics and the corresponding economic parameters of this boiler in order to be able to simulate the overall supply chain "from well to wheel". Table III gathers data such as the capacity, the efficiency and on the other hand the total investment and the fixed and variable costs.

Table III. - Technical and Economic Data for Boiler

\begin{tabular}{|c|c|c|}
\hline Technical Data & Units & \\
\hline Effective capacity & $\mathrm{kW}_{\text {th }}$ & 5000 \\
\hline Efficiency & $\%$ & 85 \\
\hline Utilization time & $\mathrm{h} / \mathrm{a}$ & 5000 \\
\hline Economic Data & Units & \\
\hline Total investment & $€ / \mathrm{kW}_{\text {th }}$ & 450 \\
\hline Fixed cost & $\%$ Invest/a & 2.7 \\
\hline Variable costs & $€ / M W h$ & 1.2 \\
\hline
\end{tabular}

Amortization period of 15 years, interest rate of $6 \%$ and personal costs rate of $50,000 € / a$.

\section{B. Heat and power station with noncondensing turbine}

A heat and power station with noncondensing turbine (back-pressure turbine) is the most suitable heat generation system for producing an important portion of steam for industrial use as well as power to a lesser extent. For this purpose such a heat power unit was analyzed in this investigation, however taking into account that this HPS is exclusively fueled with wood chips.

The technical and economic parameters of this technology have been collected for being showed in Table IV [8].

Table IV. - Technical and Economic Data for HPS (Noncond. Turbine)

\begin{tabular}{|c|c|c|}
\hline Technical Data & Units & \\
\hline Electric capacity & $\mathrm{kW}_{\mathrm{el}}$ & 5 \\
\hline Thermic capacity & $\mathrm{kW}_{\mathrm{th}}$ & 23,9 \\
\hline Electric efficiency & $\%$ & 14 \\
\hline Total efficiency & $\%$ & 81 \\
\hline Utilization time & $\mathrm{h} / \mathrm{a}$ & 6000 \\
\hline Economic Data & Units & \\
\hline Total investment & $€ / \mathrm{kW}_{\mathrm{el}}$ & 3850 \\
\hline Fixed costs & $\%$ Invest/a & 3.5 \\
\hline Variable costs & $€ / \mathrm{MWh}_{\mathrm{el}}$ & 3.8 \\
\hline
\end{tabular}




\section{Power station operated with condensing turbine}

The most used and less complex power station is undoubtedly the power unit provided with a steam noncondensing turbine without cogeneration of heat. This system actually corresponds to what is scientifically known as the steam Rankine cycle and is completely extended worldwide all through the energy generation sector. The fact of not using the heat produced by the steam turbine means diminishing the overall efficiency and hence the profitability of the plant. The same technology including the cogeneration of heat would contribute an elevated performance so that biomass supply chain could be further optimized. The following Table $\mathrm{V}$ collects the main technical and economic characteristics concerning this power station [8].

Table V. - Technical and Economic Data for PS (Condensing Turbine)

\begin{tabular}{lcc}
\hline \multicolumn{1}{c}{ Technical Data } & Units & \\
\hline Electric capacity & $\mathrm{kW}_{\mathrm{el}}$ & 20 \\
Thermic capacity & $\mathrm{kW}_{\mathrm{th}}$ & 0 \\
Electric efficiency & $\%$ & 27 \\
Total efficiency & $\%$ & 27 \\
Utilization time & $\mathrm{h} / \mathrm{a}$ & 7000 \\
\multicolumn{1}{c}{ Economic Data } & $\mathrm{Units}$ & \\
& & \\
\hline Total investment & $€ / \mathrm{kW} \mathrm{el}_{\mathrm{el}}$ & 2200 \\
Fixed costs & $\% \mathrm{Invest/a}$ & 3.5 \\
Variable costs & $€ / \mathrm{MWh}_{\mathrm{el}}$ & 6.2 \\
\hline \hline
\end{tabular}

Amortization period of 15 years, interest rate of $6 \%$, remuneration from cogeneration of heat at $3.5 € \mathrm{cent} / \mathrm{kWh}_{\mathrm{th}}$ and personal costs rate of 50,000 $€ / a$

\section{Gasification process and block heat and power station}

The gasification of wood biomass is a promising and efficient technology. The gas obtained from the wood subjected to the gasification process is after fed into the gas engine of the block heat and power station.

Table VI. - Technical and Economic Data for Gasificator and BHPS

\begin{tabular}{|c|c|c|}
\hline Technical Data & Units & \\
\hline Capacity of gasificator & $\mathrm{kW}_{\text {gas }}$ & 5000 \\
\hline Efficiency of gasificator & $\%$ & 70 \\
\hline Electric capacity & $\mathrm{kW}_{\mathrm{el}}$ & 1900 \\
\hline Thermic capacity & $\mathrm{kW}_{\text {th }}$ & 2500 \\
\hline Electric efficiency & $\%$ & 38 \\
\hline Total efficiency & $\%$ & 88 \\
\hline Utilization time & $\mathrm{h} / \mathrm{a}$ & 6000 \\
\hline Economic Data & Units & \\
\hline Total investment & $€ / \mathrm{kW}_{\mathrm{el}}$ & 3120 \\
\hline Operating costs BHPS & $\%$ Invest/a & 2 \\
\hline Operating costs gasificator & $\%$ Invest/a & 4 \\
\hline
\end{tabular}

The generated power and heat can assure the profitability of the plant, although the efficiency of the gasificator plays a relevant role throughout the overall generation process. Table VI shows all the required parameters used to analyze this HPS [8].

\section{E. Biomass integrated gasification combined cycle}

The gas cycle of a combined cycle is powered with the gas obtained from the wood submitted to an integrated gasification process. The gasificator is operated with a system based on low-pressure fluidized bed gasification technology with a pressure of 1.5 bar.

The most important technical characteristics as well as the corresponding economic parameters of this biomass integrated gasification combined cycle are showed in Table VII [8].

Table VII. - Technical and Economic Data for Gasificator and CC

\begin{tabular}{|c|c|c|}
\hline Technical Data & Units & \\
\hline Capacity of gasificator & $\mathrm{kW}_{\text {gas }}$ & 22500 \\
\hline Efficiency of gasificator & $\%$ & 85 \\
\hline Electric capacity & $\mathrm{kW}_{\mathrm{el}}$ & 8000 \\
\hline Thermic capacity & $\mathrm{kW}_{\text {th }}$ & 12440 \\
\hline Electric efficiency & $\%$ & 36 \\
\hline Total efficiency & $\%$ & 92 \\
\hline Utilization time & $\mathrm{h} / \mathrm{a}$ & 6000 \\
\hline Economic Data & Units & \\
\hline Total investment & $€ / \mathrm{kW}_{\mathrm{el}}$ & 2240 \\
\hline Operating costs BHPS & $\%$ Invest/a & 2 \\
\hline Operating costs gasificator & \%Invest/a & 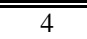 \\
\hline
\end{tabular}

\section{Different logistic chains for provision of wood}

\section{A. Transport of logs and subsequent chipping at the conversion station}

Transportation of wood logs from forests to the conversion site is the most suitable way for transporting biomass from woodlands. The reason for this fact lies in the most efficient and cost-effective transportation due to the higher energy density and mass concentration showed by logs in relation to other wood biomass like branches of agricultural or forest wastes. Fig. 1 illustrates the overall logistic chain for the process where transportation of $\operatorname{logs}$ and the subsequent chipping at the conversion station precede the conversion into energy [2], [9]. 


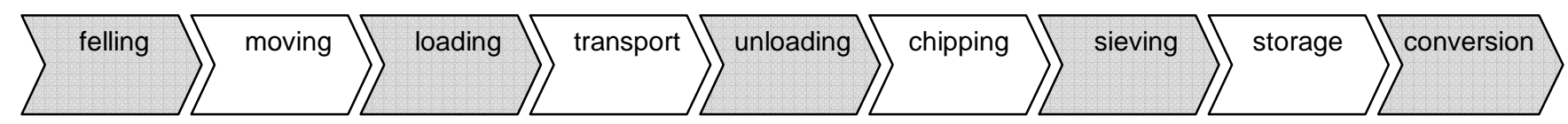

Fig. 1 Representation of the logistic chain for condensed wood biomass (transport of logs)

As an alternative logistic methodology a parallel economic study has been accomplished for wood logs chipped before being transported. For the five particular cases examined in this work covering the most representative biomass technologies for transformation of wood in energy, all the simulated cases highlighted that the chipping of logs was always less appropriate in economic terms if compared to the transportation of compact biomass. These unfavorable upshots were especially identified for the costs associated with the own value chain of this biomass product, thus resulting in higher energy costs before distribution to the net. A series of technical and economic consequences derives from this specific logistic technique, which is not recommended in general for wood transportation due to its low profitability (except for the case of branches and wastes, which will be analyzed in the following section).

\section{B. Chipping of branches and transport to conversion station}

Apart from logs the wastes from agricultural and forest origin nowadays represent another quite relevant resource of wood biomass: now in the form of branches [2], [10]. This wood product has an extremely high volume in comparison to its weight thus involving a decrease of its energy density. So far the only technical viable solution to improve this process is the chipping of these wastes before transporting them to the conversion site, thereby improving not solely the efficiency of the transportation process but also that of the overall value chain.

The logistic chain of branches and all kind of low density biomass derived from forests and cultivated areas appears in Fig.2 [2], [11]. As indicated before the chipping process precedes the transportation (unlike the logistic chain of $\operatorname{logs}$ ) so as to increase the profitability of the biomass value chain.

The logistic ideal of successively increasing the energy density could realistically be attained through the elimination of the empty spaces - containing only air - from biomass bulk. This possibility actually seems to arise with the introduction of a process of condensation/compaction of branches in order to maximize its energy density. This new more condensed and compacted state of wood biomass might really be identified with certain already existing biomass products behaving under these conditions. Pellets, briquettes or even the bundles mechanically shaped with wood wastes or branches harvested from short rotation plantations obey this idea. Hence they should be analyzed in greater detail as far as their respective logistic chain is concerned from an economic and technical point of view in order to study in depth the technical and economic feasibility of such processes. A study dealing with this topic is next qualitatively analyzed although a quantitative analysis has not been realized because it exceeded the main objective of this publication.

A connection and comparison to this issue is established through the analysis of the logistic chain of bundled wood obtained from short rotation plantations. Due to the similarities arising between both processes - i.e. the removing of the wood branches in forests and, on the other hand, the harvesting of these wood crops - an exhaustive study is to be suggested with the aim of gaining an insight into the different ways of increasing the profitability and efficiency all along the logistic chain of such cultivated raw material (e.g. poplar, willow) in order to adapt its methodology to the case of the wood raw material.

\section{Economic analysis of the logistic chains}

\section{A. Costs analysis of energy obtained from logs}

The value chain of logs from forests and agricultural areas consists of a series of elements which form a logistic chain going from felling this biomass raw material until the generation of heat and power. As described before this logistic process introduces a relatively long sequence of steps, each being associated with comparatively higher costs ( $€$ cent $/ \mathrm{kWh}$ ) in comparison to those involved for the processing of branches. The reason for these higher costs lies not only in the larger dimension of the chain (up to nine instead of six steps) but as well in the existence of some steps which are extremely cost-intensive like felling, moving of logs and the corresponding processes of loading and unloading.

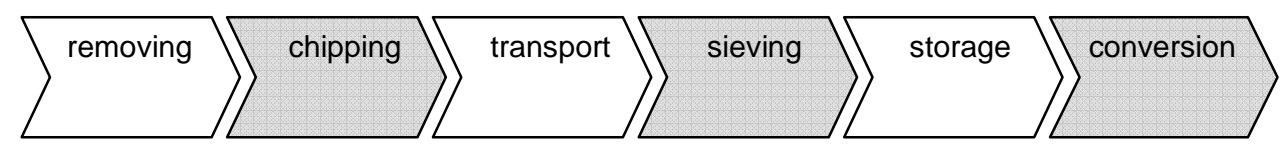

Fig. 2 Representation of the logistic chain for not condensed wood biomass (chipping of branches) 
On the contrary the transportation costs - actually only a simple element of this sequence - appear to be quite moderate if compared with those related to the transport of chips from branches. A clear ground explaining this fact is obviously the higher energy density of logs with regard to that of chips thereby entailing lower transportation costs per $\mathrm{kWh}$ as showed in Table VIII.

\begin{tabular}{|c|c|c|}
\hline & \multicolumn{2}{|c|}{ LOGISTIC CHAIN } \\
\hline & $\begin{array}{c}\text { Logs } \\
(€ c e n t / k W h \cdot k m)\end{array}$ & $\begin{array}{l}\text { Chipped Branches } \\
(€ c e n t / k W h \cdot k m)\end{array}$ \\
\hline Boiler & 0.0092 & 0.0161 \\
\hline Noncondensing turbine & 0.0563 & 0.0979 \\
\hline P.S. $20 \mathrm{MW}$ el & 0.0291 & 0.0508 \\
\hline Gasification + BHPS & 0.0296 & 0.0515 \\
\hline Gasification $+C C$ & 0.0257 & 0.0448 \\
\hline
\end{tabular}

The two aspects discussed above really determine the entire economy of the heat and power stations presented at the beginning of this work. The generation of heat and power is conditioned to a great extent by some technical parameters like the efficiency of the plants and as well as the type of the final energy carrier generated by the facility, i.e. heat or electricity.

For those stations only generating heat and consequently not receiving the corresponding subsidies the price of heat before distribution to the net and discounting the transportation costs from this quantity - is particularly high especially for the logistic chain of logs as showed in Table IX. In the sole case subjected to these conditions (the boiler) these "energy costs without transportation costs" derived from Table IX are somewhat below the reference production costs of heat generated with fossil fuels (3.5 $€$ cent $/ \mathrm{kWh}$ ). Hence there is a small margin to compete with fossil heat (although transportation costs for the logistic chain of logs are relatively economical), thereby the increasing of transportation costs with the distance speedily reaches the fossil reference costs.

\begin{tabular}{lcc}
\multicolumn{3}{c}{ Table IX. - Energy Costs without Transport Costs } \\
\hline \hline \multicolumn{2}{c}{ LOGISTIC CHAIN } \\
Logs & $\begin{array}{c}\text { Chipped Branches } \\
(€ c e n t / k W h)\end{array}$ \\
\hline Boiler & $(€ c e n t / k W h)$ & 3.21 \\
Noncondensing turbine & 3.47 & -5.40 \\
P.S. 20 MW & -3.87 & 2.33 \\
Gasification + BHPS & 2.41 & -0.97 \\
Gasification + CC & -0.17 & -3.81 \\
\hline \hline
\end{tabular}

The energy costs are referred to those production costs arisen before the distribution to the net and including the subsidies.

Fig. 3 and Table $\mathrm{X}$ illustrate how for the boiler but likewise for the block heat and power station with gasification the maximum distances that logs can be transported - assuming the reference of $0 €$ cent $/ \mathrm{kWh}$ as no benefit for the investors - do not exceed respectively the mere $5 \mathrm{~km}$ and $7 \mathrm{~km}$ on account of the low amount of heat produced (rewarded with $3.5 €$ cent $/ \mathrm{kWh}$ ) in comparison to the other technologies. On the other hand for the logistic chain of chipped branches Table X and Fig.4 make clear a considerable increment of the profitable distances for the transportation of chips in the case of both technologies due to the comparatively lower costs of the logistic chain (although the transportation costs are considerably higher according to Table VIII).

On the contrary the power stations with a noncondensing turbine and the biomass integrated gasification combine cycle demonstrate how the large contribution of heat produces enough gains to have low energy costs for the logistic chains (discounting the transport cost) thus permitting to reach the reference level of 0 €cent $/ \mathrm{kWh}$ through quite long distances.

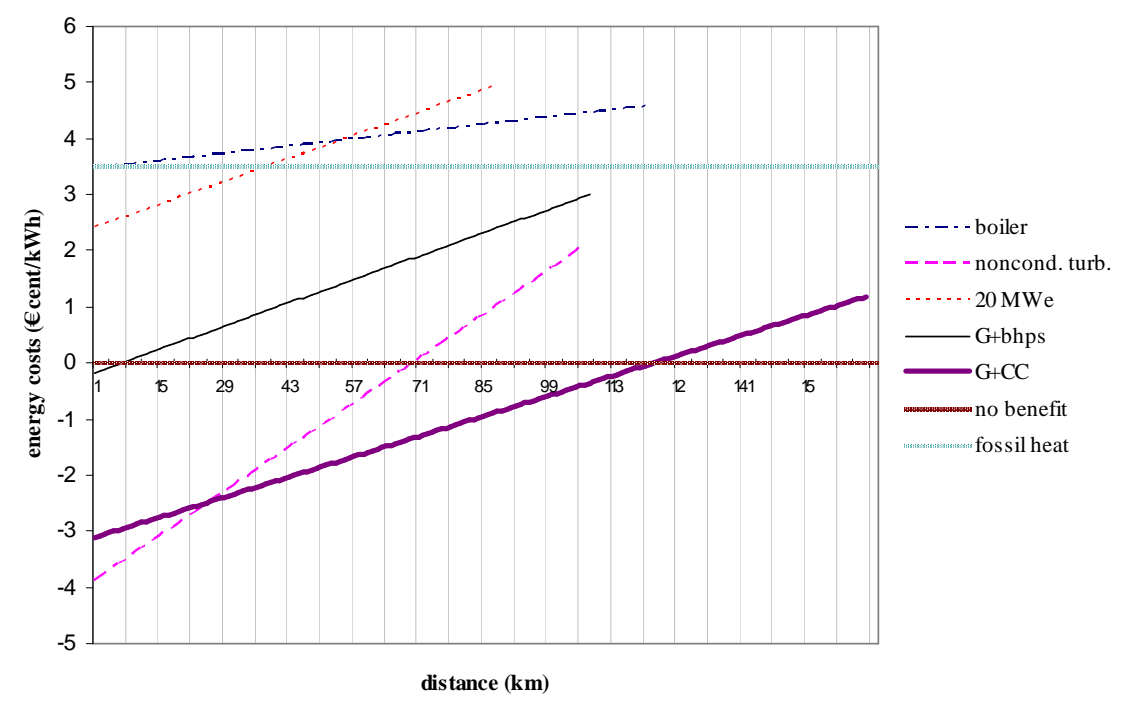

Fig. 3 Dependence of energy costs on the covered distance in the case of transportation of logs to conversion site 


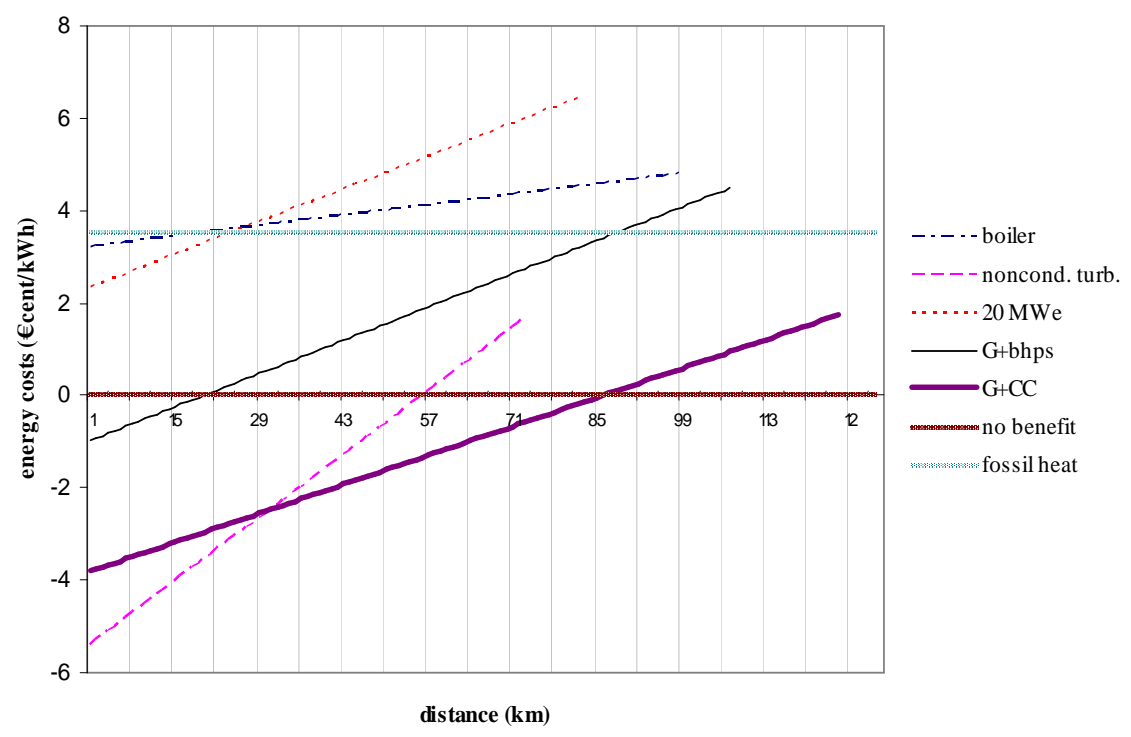

Fig. 4 Dependence of energy costs on the covered distance for the transportation of chipped branches to conversion site

\section{B. Costs analysis of energy obtained from branches}

The logistic chain of chipped branches is characterized by an economic behavior completely opposite to that of the before treated chain of logs. The branches have to be anyways chipped to merely increase their extremely low energy density. Nevertheless after the chipping process this physical property still continues to be quite low regarding that of logs what consequently means that the transportation costs of chips will be considerably higher than in the case of logs.

In contrast with that the costs derived from the rest of the logistic chain (discounting the transportation costs) are not as high as those for logs as detailed in Table IX. Fig. 2 gives the reasons to understand this reality: on the one hand the number of steps has been reduced to only six and one of the most cost-intensive steps (felling) of the logistic chain of logs is eliminated. Then again, there is a new bulk material - chips - the processing of which all along the value chain is much easier and therefore more economical and so more profitable.

Table X. - Profitable Distance for Transportation of Wood

\begin{tabular}{|c|c|c|}
\hline & \multicolumn{2}{|c|}{ LOGISTIC CHAIN } \\
\hline & $\begin{array}{l}\text { Logs } \\
(\mathrm{km})\end{array}$ & $\begin{array}{l}\text { Chipped Branches } \\
(\mathrm{km})\end{array}$ \\
\hline Boiler & 5 & 19 \\
\hline Noncondensing turbine & 70 & 56 \\
\hline P.S. $20 \mathrm{MW}$ el & - & - \\
\hline Gasification + BHPS & 7 & 20 \\
\hline Gasification $+C C$ & 122 & 86 \\
\hline
\end{tabular}

Table $\mathrm{X}$ highlights that the longest distances under profitable conditions are accomplished for the same heat and power stations (noncondensing turbine, gasification
C.C.) as in the case of logs although relatively lower due to the less efficiency of transportation of chips (Table VIII).

The heat and power station with a noncondensing turbine also produces electricity but in a lower quantity compared to the main objective of this technology: the heat generation. Therefore the great amount of heat allows meeting relatively good results for the biomass transportation distance, thereby reaching approximately 56 $\mathrm{km}$ for the logistic chain of chips (in general the least economical one respecting the transportation costs but showing a quite low value for the magnitude "energy costs without transport costs" from Table IX).

Lastly the development state of the technology applied to the conversion step as well as the investment and operating costs of each heat and power station determine to a large extent the final value obtained for the energy costs of the different technologies.

\section{Implementation of a wood supply system}

\section{A. Conceptual approach}

The feasibility and the corresponding implementation of an energy supply system based on biomass are continually threatened by the widely applied and completely costeffective oil-derived fuels. On account of the necessity of transport means for transferring biomass from forests and fields to conversion or storage sites a transportation planning analysis is required in order to assess the potential and opportunities in competition with other energy carriers.

Therefore an analysis of maximum transportation distances - i.e. those allowed for a profitable enough distribution of 
biomass - should be the basis for the construction of a suitable transportation system of biomass in general and of wood in particular for the present work.

\section{B. Construction of decentralized grids of biomass supply}

This restriction concerning optimal transportation distances within the framework of the wood supply planning introduces a concentric model whereby the forests and fields would be located around a conversion site or a decentralized storage spot and where the radii $R$ coincide with the unreal distances between both points drawn "as the crow flies".

According to (1) the radius $R$ has to be multiplied by a parameter called diversion factor $f$ [3], which characterizes the divergence degree of the real route $D$ realized in the transportation process from the straight line described by that geometric space.

$$
D=f \cdot R
$$

The diversion factor varies from a region to another and is related to the kind of route used for transporting the biomass. Typical values for $f$ range from 1.2 to 1.5 depending on the physical and geometric characteristics of the road covered by the truck.

Fig. 5 shows how a wood supply system could be outlined according to these above mentioned principles. The main idea of this model introduces the construction of a decentralized grid constituted by interconnected units in a same aggregation level. The relatively short distances to be covered due to the low profitability of biomass transportation would justify this grid configuration instead of the usual great centralized nets established for great regions like in the case of fossil fuels where the low prices (economy of scale) allow reaching large distances.

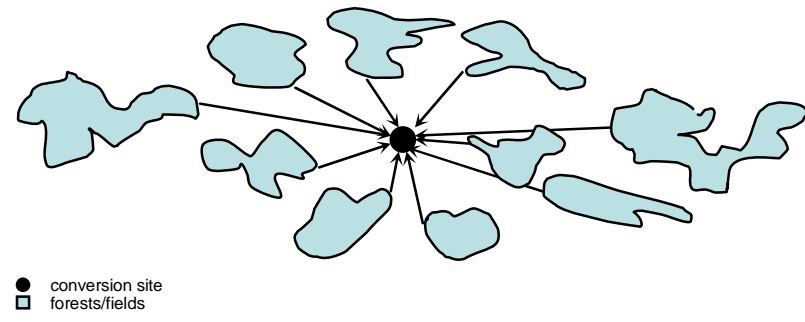

Fig. 5 Outline of decentralized provision of wood

\section{Conclusions}

There exist two different logistic chains for collecting the wood biomass and then converting it into power and heat. The logs as condensed energy carriers and the branches resulting from lopping processes in forests and agricultural areas constitute the basis of the current provision of wood.
The analysis of both value chains raises certain advantages and disadvantages regarding the wood transportation by truck and its corresponding profitability.

The analysis of the potentiality of the energy production in certain forestry and agricultural regions advises the implementation of decentralized biomass-based heat and power generation. The system will be constituted by a set of spread nodes, each acting as a HPS within a grid configuration.

The results of the simulation model used inevitably point out to a necessary approval or - if already existent - an increase of subsidies and incentives regarding biomass-fired heat power plants. Moreover, the heat produced at the HPS should be conducted to a potentially growing industrial sector built up around the facility, thus taking advantage of synergies between energy generation and other industrial activities (tourism, tin industry, etc).

\section{References}

[1] C. N. Hamelink, R.A. Suurs, A.P. Faaij, "International bioenergy transport costs and energy balance", Copernicus Research Institute for Sustainable Development and Innovation, Utrecht University, Biomass and Bioenergy, Elsevier, 2005, pp. 117-125

[2] K. Dovers, S. Opitz, "Biologio. Entwicklung und Ausbau regionaler Logistikstrukturen für Holzbrennstoffe", Fraunhofer Institut Materialfluss und Logistik IML, 2007, pp. 89-106

[3] S. Frick, F. Müller-Langer, D. Thrän, "Bereitstellung biogener Festbrennstoffe zur Strom- und Kraftstofferzeugung - Bewertung unterschiedlicher Logistikansätze", Institute for Energy and Environment, 2005, pp. 58-85, Appendix A-22

[4] "Leitfaden Bioenergie: Planung, Betrieb und Wirtschaftlichkeit von Bioenergie“, Fachagentur Nachwachsende Rohstoffe. 4. Edition, 2007.

[5] "German Act for Renewable Energies (EEG)", Federal Ministry for Environment, Protection of Nature and Security for Reactors, 2004.

[6] "Bioenergie Basisdaten Deutschland", Fachagentur Nachwachsende Rohstoffe e. V., 2008.

[7] "Handlungskonzept zur energetischen Nutzung von Holz im Kreis Unna und Umgebung", Energieagentur Lippe GmbH, 2005 , p. 24

[8] J. Nitsch, S. Gärtner, "Ökologisch optimierter Ausbau der Nutzung erneuerbaren Energien in Deutschland", Federal Ministry for Environment, Protection of Nature and Security for Reactors, 2004, pp. 35-45

[9] S. Wittkopf, "Bereitstellung von Hackgut zur thermischen Verwertung durch Forstbetriebe in Beyern", Dissertation, Chair for Forestry Sciences and Applied Informatics, University of Munich, 2005.

[10] C. Kanzian, B. Fenz, F. Holzleitner, K. Stampfer, "Waldhackguterzeugung aus Schlagrücklass", Department of Forest and Land Sciences, University für Bodenkultur Wien, 2005, pp. 13-14

[11] "Woodchip fuel specifications and procurement strategies for the Black Hills", Biomass Energy Resource Center, Montpelier, 2007. 